\title{
Do Primacy, Recency and Experimental Amnesia also Exist for Odor Names
}

M. Bensafi, C. Rouby and A. Holley

\section{(2) OpenEdition}

1 Journals

\section{Electronic version}

URL: http://journals.openedition.org/cpl/204

DOI: $10.4000 / \mathrm{cpl} .204$

ISSN: $1379-6100$

\section{Publisher}

Centre PsyCLÉ

Printed version

Date of publication: 1 August 2002

\section{Electronic reference}

M. Bensafi, C. Rouby and A. Holley, «Do Primacy, Recency and Experimental Amnesia also Exist for Odor Names ", Current psychology letters [Online], 2002/2, 8 | 2002, Online since 05 September 2003, connection on 08 September 2020. URL : http://journals.openedition.org/cpl/204 ; DOI : https:// doi.org/10.4000/cpl.204

This text was automatically generated on 8 September 2020.

(C) All rights reserved 
Do Primacy, Recency and Experimental Amnesia also Exist for Odor Names

M. Bensafi, C. Rouby and A. Holley 